\title{
ĐỊNH HƯớNG MỘT NỀN KINH TẾ TUẦ HOÀN TRONG THỜI KỲ CÁCH MẠNG CÔNG NGHỆ 4.0
}

\section{Trần Hồng Hà ${ }^{1}$}

Tóm tắt: Việt Nam, sau một thời gian dài phát triển dựa vào các nguồn tài nguyên, lao động giá rẻ, đã đạt được nhiều về phát triển kinh tế-xã hội. Tuy nhiên, nước ta đang phải đối mặt với nhiều thách thức nghiêm trọng về cạn kiệt tài nguyên, ô nhiếm môi truò̀ng và biến đổi khi hậu. Vì thế Việt Nam cần thể hiện trách nhiệm trong giải quyết những thách thức toàn cầu do ô nhiếm môi truòng, biến đổi khi hậu, nâng cao súc cạnh tranh của nền kinh tế. Xây dựng một xã hội có ý thức tận dụng được nguồn nguyên vật liệu đã qua sử dụng thay vì tiêu tốn chi phí xủ lý, giảm thiểu khai thác tài nguyên thiên nhiên, tận dụng tối đa giá trị tài nguyên, hạn chế tối đa chất thải, khi thải ra môi truờng, bảo vệ sức khoẻ người dân. Cần định hướng xây dựng nền kinh tế theo xu hướng tiên tiến để giảm rủi ro về khủng hoảng thừa sản phẩm, khan hiếm tài nguyên, tạo ra co hội việc làm và đầu tu mới, giảm chi phí sản xuất, tăng chuỗi cung ứng. Xuất phát tù tình hình thực tế của Việt Nam và kinh nghiệm tù các nuoớc tiên tiến, kinh tế tuần hoàn là giải pháp hũu hiệu để phát triển bền vũng kinh tế - xã hội của đất nước, phù hợp với điều kiện các nguồn tài nguyên hạn chế và đang dần cạn kiệt, môi trường đang bị suy thoái. Việt Nam cần tập trung truển khai các giải pháp nhằm thúc đẩy sự chuyển dịch tù Kinh tế tuyến tính sang Kinh tế tuần hoàn. Bài báo này đura ra nhũng co sở định hướng nhằm thúc đẩy phát triển kinh tế tuần hoàn cho Việt Nam được xem nhu là một tất yếu của quá trình phát triển.

Tù̀ khóa: Kinh tế tuần hoàn, Cạn kiệt tài nguyên, Ô nhiễm môi trường, Biến đổi khí hậu, Phát triển bền vĩng.

Ban Biên tập nhận bài: 11/12/2019 Ngày phản biện xong: 12/12/2019 Ngày đăng bài: 20/12/2019

\section{Mở đầu}

Mô hình phát triển kinh tế truyền thống, hay còn gọi là kinh tế tuyến tính (Linear Economy) có đặc điểm Khai thác tài nguyên từ môi trường tự nhiên làm đầu vào cho hệ thống kinh tế, qua quá trình Sản xuất, Tiêu dùng và cuối cùng Thải loại ra môi trường, dẫn đến gia tăng chất thải, cạn kiệt tài nguyên thiên nhiên và gây ô nhiễm, suy thoái môi trường, vượt qua giới hạn sức chịu tải của môi trường. Năm 2018, Mạng lưới Dấu chân toàn cầu GFN ước tính nhu cầu về tài nguyên thiên nhiên cho các hoạt động kinh tế của con người hiện nay đã gấp 1,7 lần khả năng đáp ứng của trái đất [1]. Vì thế, nếu không thay đổi cách thức phát triển, việc cạn kiệt tài nguyên là không thể tránh khỏi. Về rác thải, chỉ tính riêng rác thải nhựa đổ ra biển của thế giới năm 2014 đã là 150 triệu tấn; dự đoán đến năm 2050 nếu không có những giải pháp hữu hiệu, tổng khối lượng rác thải nhựa thậm chí sẽ nhiều hơn tổng khối lượng cá trong các đại dương [2]. Với Việt Nam, hiện nay chúng ta đang phải đối mặt với các vấn đề về tài nguyên và môi trường, hậu quả của mô hình kinh tế tuyến tính, nổi lên là:

i) Tiêu thụ năng lượng tăng nhanh và suy giảm tài nguyên: Tiêu thụ năng lượng của Việt Nam trong nhiều năm trở lại đây tăng gấp đôi so với tốc độ tăng trưởng GDP khiến kể từ năm 2015, Việt Nam đã trở thành nước nhập khẩu ròng năng lượng [3]. Nhiều tài nguyên hiện đang suy giảm nghiêm trọng, tiêu biểu là than đá (Hình 1).

Từ một nước vẫn tự hào về xuất khẩu than, Việt Nam bắt đầu phải nhập than từ năm 2001 và đến năm 2015 đã trở thành nước nhập khẩu ròng than (lượng nhập khẩu lớn hơn xuất khẩu).

${ }^{1}$ Ủy viên Ban chấp hành Trung uoong Đảng, Bộ trương Bộ Tài nguyên và Môi trương

Email:thha@monre.gov.vn 


\section{BÀI BÁO KHOA HỌC}

Dự báo tới năm 2030, nước ta có thể phải nhập khẩu tới 100 triệu tấn than mỗi năm [4]. Ngoài than đá thì Việt Nam còn phải liên tục tăng nhập khẩu dầu thô, thậm chí sắt thép, các kim loại thường, chất dẻo nguyên liệu, nguyên phụ liệu cho dệt may và da giày (Hình 2).

Triệu tấn

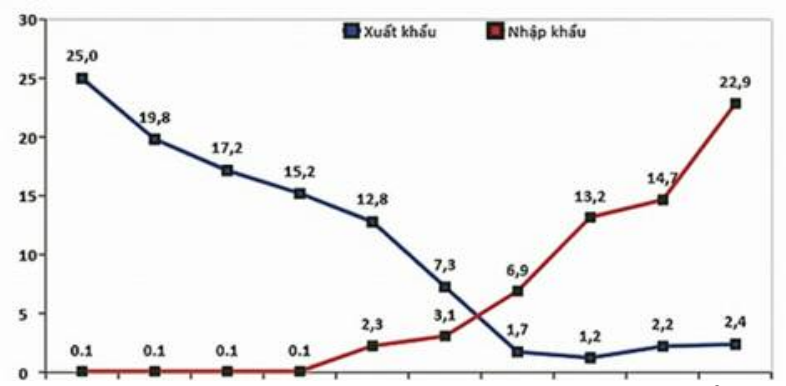

Hìn 1. Việt Nam trở thành nước nhập khẩu ròng than kể tù̀ năm 2015 [4-5]

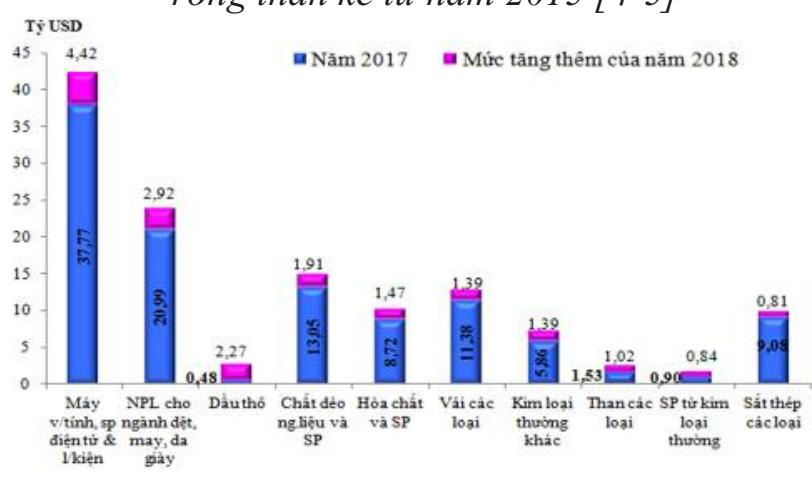

Hình 2. Các nhóm hàng nhập khẩu có mức tăng về giá trị lớn nhất trong năm 2018 (Nguồn: Báo cáo của Tổng cuc hái quan (2019))

Rõ ràng, các tài nguyên của chúng ta đang bị suy giảm, không đáp ứng được nhu cầu phát triển kinh tế trong nước;

ii) Phát thải tăng nhanh: Theo Bộ Tài nguyên và Môi trường, năm 2009, chất thải rắn thông thường phát sinh khoảng 28 triệu tấn/năm [6] và khảo sát mới đây cho thấy chất thải rắn phát sinh là 37 triệu tấn. Trên phạm vi toàn quốc, chất thải rắn phát sinh ngày càng tăng với tốc độ gia tăng khoảng $10 \%$ mỗi năm và còn tiếp tục gia tăng mạnh trong thời gian tới cả về lượng và mức độ độc hại [7]. Riêng đối với chất thải rắn sinh hoạt đô thị, ước tính phát sinh trên toàn quốc tăng trung bình từ 10-16\% mỗi năm [8]. Theo báo cáo gần đây của Ngân hàng thế giới World Bank, chất thải rắn đô thị của Việt Nam năm 2016 là 11,6 triệu tấn, dự báo năm 2030 là 15,9 triệu tấn, tăng 38\% so với năm 2016 [9]. Đặc biệt, mặc dù chỉ xếp thứ 68 thế giới về diện tích, thứ 15 thế giới về dân số, nhưng Việt Nam hiện xếp đứng thứ 4 thế giới về rác thải nhựa, với 1,83 triệu tấn/năm [10] (Hình 3);

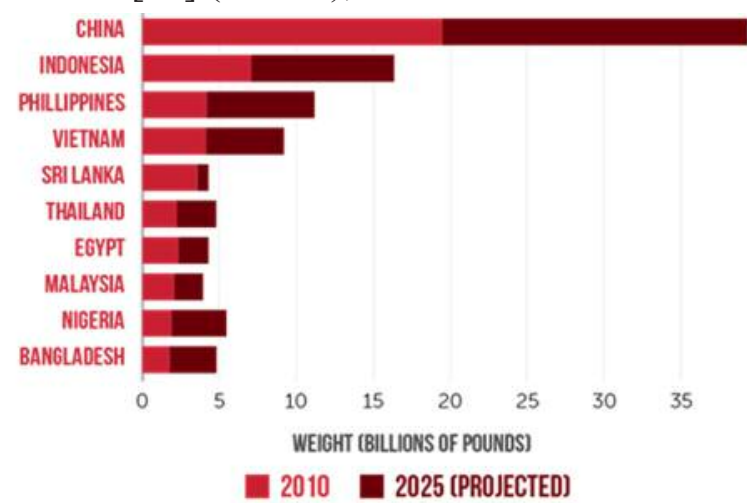

Hình 3. Việt Nam đưng thứ 4 thế giới về rác thải nhựa thải ra biển [10]

iii) Tái sử dụng, tái chế còn hạn chế: Cho đến nay, vấn đề phân loại rác tại nguồn vẫn chưa được triển khai mở rộng. Chất thải rắn sinh hoạt được xử lý chủ yếu bằng phương pháp chôn lấp lộ thiên hoặc lò đốt chất thải. Tỷ lệ chất thải rắn sinh hoạt được giảm thiểu hoặc tái chế tại các cơ sở xử lý đạt khoảng 42\% [8]. Một số ngành được coi là có khả năng tái chế cao, trên thực tế vẫn còn nhiều hạn chế ở chính khía cạnh này. Tiêu biểu là ngành giấy. Hình 4 cho thấy sản lượng giấy của Việt Nam tăng lên không ngừng qua thời gian, đặc biệt là giai đoạn sau năm 2007 khi Việt Nam bắt đầu gia nhập tổ chức Thương mại thế giới;

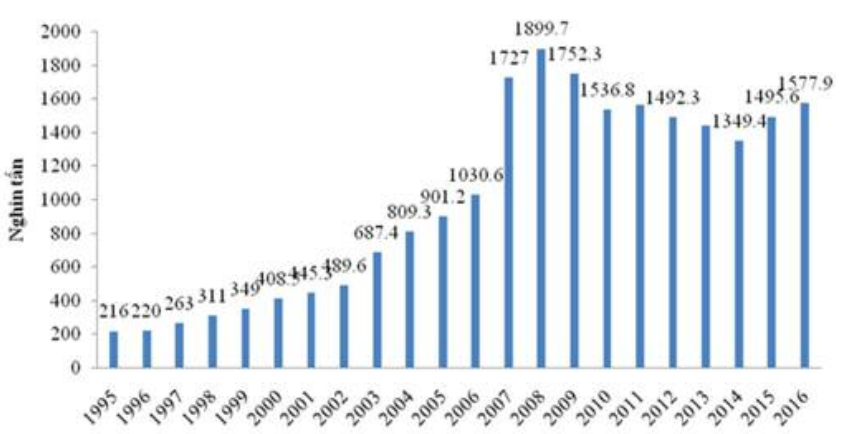

Hình 4. Sản lượng giấy của Việt Nam tù năm 1995 đến năm 2015 (Nguồn: Niên giám thống kê 2017)

iv) Ô nhiễm môi trường gây thiệt hại nghiêm trọng: Theo World Bank [11], chỉ riêng ô nhiễm không khí đã khiến Việt Nam mất đi 5,18\% GDP của năm 2013. Ô nhiễm nước cũng có thể gây thiệt hại cho Việt Nam tới 3,5\% GDP vào năm 
2035 [12]. Đó là chưa tunhs tới ô nhiễm đất, và suy thoái đất đang ảnh hưởng nghiêm trọng tới hoạt động sản xuất nông nghiệp, vốn là nghề truyền thống bao năm qua của phần lớn người dân Việt Nam. Một số năm gần đây, các sự cố môi trường từ việc xả thải của các nhà máy, như các vụ việc của nhà máy Vedan, công ty Formosa Vũng Áng, công ty cổ phần mía đường Hòa Bình,... gây thiệt hại lớn tới hệ sinh thái những khu vực bị ô nhiễm. Đặc biệt, Việt Nam nằm trong số các quốc gia dễ bị tổn thương nhất do biến đổi khí hậu [13-14]. Năm 2010, biến đổi khí hậu và thiên tai đã gây thiệt hại 5,14\% GDP của Việt Nam, và con số này có thể lên tới $11 \%$ vào năm 2030 [15] (Hình 5).

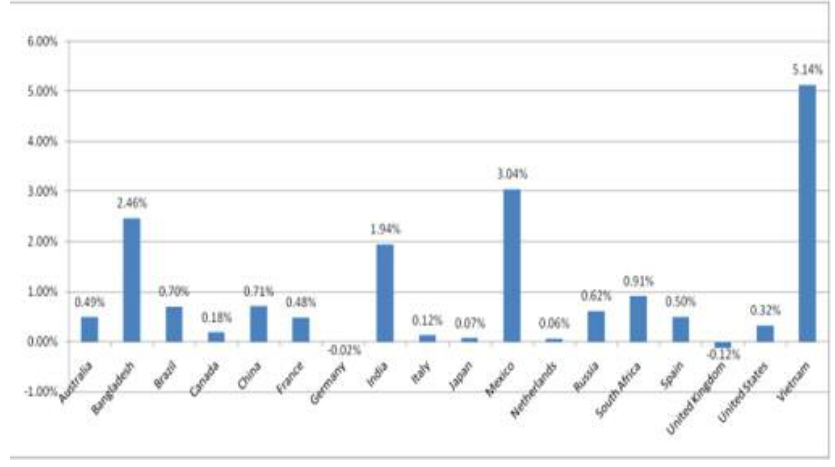

Hình 5. Thiệt hại do biến đổi khí hậu và thiên tai so với GDP của môt số nước [15]

\section{Nguyên lý của nền kinh tế tuần hoàn}

Trước những vấn đề trên, nhiều nước hiện nay đang thực hiện chuyển đổi sang nền Kinh tế tuần hoàn (Circular Economy), Việt Nam cũng không thể nằm ngoài xu thế đó. Kinh tế tuần hoàn dựa trên nguyên lý động lực học, nhất là định luật bảo toàn vật chất và năng lượng, với cốt lõi là kết nối điểm cuối với điểm đầu của quá trình kinh tế, giúp các vật liệu được thu hồi trở lại thành đầu vào cho hệ thống kinh tế (Hình 6).

Kinh tế tuần hoàn $(\mathrm{KTTH})$ đã sớm được đưa ra từ những năm 60 và 70 của thế kỷ trước bởi một số nhà kinh tế môi trường và kinh tế sinh thái [17]. Thực hiện KTTH sẽ giúp đồng thời thực hiện các mục tiêu kinh tế, môi trường và xã hội. Ước tính thực tế tại Châu Âu, Kinh tế tuần hoàn có thể tạo ra lợi ích 600 tỉ Euro mỗi năm,
580.000 việc làm mới và giúp giảm phát thải khí nhà kính [18-19]. KTTH hiện nay không chỉ là 3R (giảm thiểu, tái sử dụng, tái chế) mà quan trọng là tái tạo và khôi phục, thông qua thiết kế (bao gồm cả thiết kế chất thải). KTTH không phải là một mô hình đồng nhất cho cả nền kinh tế, mà đó là nền kinh tế có chứa các mô hình KTTH (mô hình tuần hoàn vật liệu trong sản xuất sản phẩm, mô hình tuần hoàn trong chuỗi cung ứng,..). Vì thế, KTTH được hình thành ngay từ những hành động nhỏ nhất. Theo đó, KTTH có 3 nội hàm cơ bản gồm: (a) Bảo tồn và phát triển vốn tự nhiên thông qua việc kiểm soát nhằm sử dụng hợp lý các tài nguyên và tái tạo các hệ thống tự nhiên; (b) Tối ưu hóa lợi tức của tài nguyên bằng cách tuần hoàn các sản phẩm và vật liệu nhiều nhất có thể trong các chu trình kỹ thuật và sinh học; (c) Nâng cao hiệu suất chung của toàn hệ thống bằng cách tối thiểu hóa các ngoại ứng tiêu cực, thậm chí thực hiện thiết kế chất thải.

Với các nội hàm kể trên, Kinh tế tuần hoàn là một cách thức chuyển đổi phù hợp trong bối cảnh thực hiện các mục tiêu của phát triển bền vững (SDGs) và ứng phó với biến đổi khí hậu. Kinh tế tuần hoàn gắn liền và hỗ trợ cho việc thực hiện 10/17 mục tiêu của phát triển biền vững, gồm SDG2, SDG6, SDG7, SDG8, SDG 9, SDG 12, SDG 13, SDG 14, SDG 15 và SDG 17.

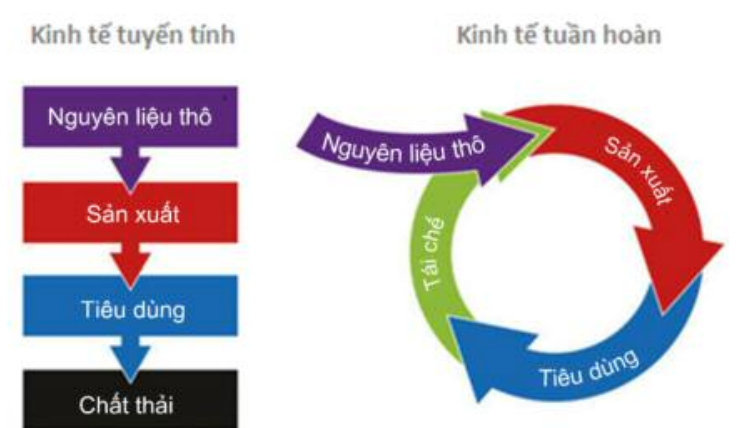

Hình 6. Kinh tế tuyến tính và kinh tế tuần hoàn [16] 


\section{Xu hướng thực hiện kinh tế tuần hoàn trên thế giới}

Hiện nay, kinh tế tuần hoàn đang trở thành một xu hướng, được thực hiện ở nhiều quốc gia trên thế giới, gồm Khối liên minh châu Âu (đi đầu là Hà Lan, Đức và Đan Mạch), châu Mỹ (tiêu biểu là Canada và Mỹ), châu Á (tiêu biểu là Trung Quốc, Nhật Bản, Hàn Quốc và Singapore). Tính tổng số đã có khoảng 34 quốc gia với 118 mô hình tiêu biểu thực hiện việc chuyển dịch này [20].

Châu Âu được biết đến là nơi hiện đang thúc đẩy KTTH mạnh mẽ nhất. Liên minh châu Âu (EU) xác định rất rõ KTTH không chỉ là vấn đề chất thải. Mặc dù dự kiến thông qua Đề xuất lập pháp về vấn đề chất thải (Legislative proposal on waste) vào năm 2014, Ủy ban Châu Âu đã tạm dừng và thay thế đề xuất này bằng Gói đề xuất Kinh tế tuần hoàn (Circular Economy package) vào năm 2015 , nhằm tiếp cận vấn đề rộng hơn, quan tâm toàn bộ các quá trình nền kinh tế, từ sản xuất và tiêu thụ thị trường nguyên liệu thứ cấp [21]. Tiếp theo đó, khối liên minh này đã triển khai Kế hoạch hành động KTTH (EU Action Plan for the Circular Economy) và Kế hoạch thiết kế sinh thái 2016-2019 (Ecodesign Working Plan 2016-2019) [22]. Từ đó, mỗi quốc gia thuộc khối cũng triển khai các hành động riêng của mình để thực hiện KTTH một cách hệ thống nhất.

Tuy nhiên trên thực tế, các chính sách liên quan đến KTTH đã xuất hiện từ trước đó rất lâu ở các quốc gia, với nhiều cách tiếp cận khác nhau. Ngay tại Châu Âu, Hà Lan đã có bước đi đầu tiên từ những năm 1970, với "thang Lansink", ưu tiên ngăn ngừa và hạn chế phát sinh chất thải, thúc đẩy tái sử dụng và tái chế, sau đó là việc xử lý rác bằng phương pháp đốt trước khi áp dụng biện pháp cuối cùng là chôn lấp [23]; tại Đức là Luật về Quản lý chất thải và Chu trình khép kín (Closed Substance Cycle and Waste Management Act) năm 1996 [24, 25]. Tại Châu Mỹ là Hoa Kỳ với các cách tiếp cận dựa vào thị trường đối với rác thải từ năm 1677 [26]. Tại Châu Á, Nhật Bản khởi xướng với Luật Cơ bản cho việc thành lập một xã hội dựa vào tái chế (The Basic Law for Establishing a RecyclingBased Society) từ năm 2002 [27]. Năm 2009, Trung Quốc cũng có Luật Xúc tiến Kinh tế tuần hoàn (Circular Economy Promotion Law) [28]. Chi tiết kinh nghiệm của một số nước tiêu biểu được trình Bảng 1.

Bảng 1. Nhũng thành tựu đạt được thông qua các hành động thực hiện KTTH của các quốc gia điển hình

\begin{tabular}{|c|c|}
\hline Quốc gia & Thành tựu đạt được thụ̣c hiện KTTH \\
\hline \multirow[t]{2}{*}{ Hà Lan } & $\begin{array}{l}\text { Điểm khởi đầu của việc tiếp cận KTTH tại Hà Lan từ năm } 1979 \text { khi đề xuất chính sách trong lĩnh vực quản lý } \\
\text { chất thải của Ad Lansink được Quốc hội thông qua. Theo đó, đề xuất này cung cấp một hệ thống phân cấp } \\
\text { trong phương pháp quản lý chất thải (còn được gọi là “thang Lansink"), ưu tiên ngăn ngữa và hạn chế phát } \\
\text { sinh chất thải, thúc đẩy tái sử dưng và tái chế, sau đó là việc xử lý rác bằng phương pháp đốt trước khi áp dụng } \\
\text { biện pháp cuối cùng là chôn lấp [23]. }\end{array}$ \\
\hline & 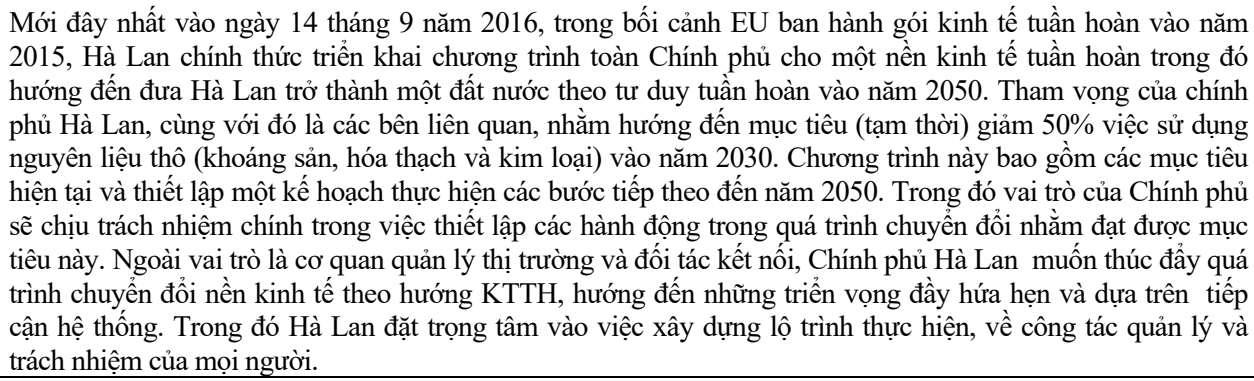 \\
\hline
\end{tabular}


Cộng hòa Đức khởi đầu khá sớm hướng tới KTTH. Quốc gia này bắt đầu thực hiện triển khai KTTH vào năm 1996. Liên bang Điều này được đi kèm với việc ban hành Đạo luật về quản lý chất thải và chu trình khép kín. Luật cung cấp Đức một khuôn khổ để thực hiện quản lý chất thải theo chu trình khép kín và đảm bảo việc xử lý chất thải tương thích với môi trường cũng như khả năng đồng hóa chất thải.

Ở cấp độ châu Âu, một số khung khổ pháp lý đã được thông qua để thúc đẩy nền KTTH khu vực, như Chỉ thị khung chất thải, Chỉ thị chôn lấp và Chỉ thị chất thải bao bì và bao bì. Theo đó, Đức áp dụng một số chiến lược để thúc đẩy cách tiếp cận thực hiện KTTH ở cấp quốc gia, bao gồm việc giảm thiểu chất thải, tái sử dụng, tái chế và đốt rác thải để sản xuất điện và nhiệt. Một nền tảng của khung chính sách tái chế của Đức là đạo luật về đóng gói (Verpackungsverordnung), được thông qua vào năm 1991 [29].

Đức cam kết giảm $40 \%$ lượng khí thải nhà kính nếu các quốc gia thành viên EU khác đồng ý với mục tiêu giảm $30 \%$ của EU vào năm 2020. Khung của mục tiêu toàn nền kinh tế này được gọi là Chương trình Năng lượng và Khí hậu Tích hợp của Đức, đưa ra các biện pháp chính sách cho ngành năng lượng. Một số chính sách để thực hiện các mục tiêu này bao gồm các biện pháp chính như Đạo luật Năng lượng tái tạo (Erneuerbare-Energiene-Gesetz, EEG) và cải cách thuế sinh thái.

Vương Đan Mạch có nhiều công ty hàng đầu tiên phong trong các giải pháp KTTH, cùng với đó là các truyền thống quôc Đan lâu đời vê các chính sách đôi mới, kích thích nên KTTH cũng như các cam kêt chiên lược lâu dài vê hiệu quả Mạch sử dụng năng lượng và năng lượng tái tạo. Đan Mạch tỏ ra vượt trội so với EU28 trên phần lớn các số liệu được lựa chọn về tài nguyên và tính sáng tạo.

Đan Mạch xác định việc chuyển đổi sang nền KTTH vẫn có thể mang lại lợi ích lâu dài cho một nền kinh tế sáng tạo hơn, bền vững và hiệu quả hơn. Những tác động tích cực đến nền kinh tế Đan Mạch trong 5 lĩnh vực (gồm thực phẩm, xây dựng, máy móc, bao bì nhựa, bệnh viện), chiếm $25 \%$ nền kinh tế [18]. Từ 5 lĩnh vực đó, Đan Mạch đã xác định ra 10 cơ hội để thực hiện KTTH. Cụ thể hơn, tiềm năng kinh tế lớn nhất được xác định ở trong các ngành Xây dựng, Bất động sản, Thực phẩm và Đồ uống.

Để triển khai KTTH với những kỳ vọng trên, Đan Mạch đã vạch ra một kịch bản ngắn hạn trong 5 năm (2020) và một kịch bản dài hạn trong 20 năm (2035 đã được xác định), trong đó mỗi kịch bản có tỷ lệ thích ứng và việc tạo ra giá trị đã được ước tính. Năm 2035 được chọn để làm năm bản lề nhằm có được một sự xem xét đánh giá đầy đủ tới các cơ hội, mà không đi quá xa cho các doanh nghiệp và bên liên quan khó khăn trong việc đánh giá các cơ hội cụ thể. Mô tả kịch bản cung cấp một bối cảnh chung để xác định và đánh giá các cơ hội khác nhau, bằng cách nói rõ cách thức môi trường kinh doanh và hành vi của người tiêu dùng, cũng như cồng nghệ, có thể phát triển trong tương lai.

Canada Cho đến nay, Canada vẫn chưa đưa ra một chiến lược về KTTH tích hợp, toàn diện, nước này chú trọng hơn về vấn đề biến đổi khí hậu và tăng trưởng sạch (Clean Growth). Tuy nhiên, Canada đã thành lập Hội đồng không chất thải quốc gia (The National Zero Waste Council). Đây được coi là một sáng kiến lãnh đạo tập hợp chính phủ, doanh nghiệp và các tổ chức phi chính phủ để thúc đẩy ngăn chặn sự xả thải và chuyển dịch sang nền KTTH ở Canada.

Hai định hướng chiến lược cũng được Hội đồng đề ra cho việc triển khai KTTH đó là:

-Thay đổi thiết kế: Thay đổi thiết kế sản phẩm và bao bì để giảm mức độ sử dụng vật chất và cho phép chúng có thể dễ dàng tái sử dụng, tái chế và thu hồi;

-Thay đổi hành vi: Thay đổi xúc tác trong hành vi, giữa tất cả các bên liên quan và các lĩnh vực của xã hội, với mục tiêu giảm lượng chất thải đầu ra;

Ngày 28 tháng 11 năm 2018, dựa theo những nguyên tắc và định hướng mà Hội đồng đề ra, Chiến lược quốc gia về Không Chất thải nhựa đã được trao đổi thảo luận ) tại hội thảo với nhiều bên liên quando Bộ Môi trường và Biến đổi khí hậu Canada (ECCC) và Bộ Y tế Canada (HC bàn về kế hoạch quản lý hóa chất Canada ở Ottawa với tầm nhìn dài hạn, giữ tất cả nhựa trong nền kinh tế, không thải ra môi trường bằng cách sử dụng cách tiếp cận KTTH.

Trong khi các chương trình quản lý chất thải trong quá khứ được đưa ra ở Canada, vẫn có hơn $89 \%$ nhựa được chôn lấp và đem đi đốt. Nhằm cải thiện tình hình trên, Chiến lược mới đưa ra một hệ thống tích hợp bao gồm ba lĩnh vực hoạt động: phòng ngừa, thu hồi dọn dẹp và phục hồi giá trị.

Hệ thống này sẽ được hỗ trợ bằng cách cho phép các hoạt động, bao gồm nâng cao nhận thức và giáo dục, nghiên cứu và đổi mới, các quy định và công cụ dựa trên thị trường (MBA). Thiết kế các sản phẩm nhựa sẽ trở thành một trong những hành động ưu tiên góp phần vào mục tiêu chung là các sản phẩm nhựa phải được tái sử dụng và tái chế $100 \%$. Canada cũng có kế hoạch giảm lượng chất thải nhựa lẫn điện tử xuất khẩu sang các nước khác với mục đích tái chế nhiều hơn trong nước [30].

Họ̣p Tại Hoa Kỳ, KTTH được hình thành trên cơ sở cách tiếp cận dựa vào thị trường. Cách tiếp cận dựa vào thị chúng trường (Market-Based Approaches - MBAs), là ngoài nhà nước, các chủ thể thị trường khác như doanh quốc Hoa nghiệp và tổ chức có tư cách pháp nhân được tự do tham gia kinh doanh và cung cấp các hàng hoá và dịch vụ Kỳ (kể cả các hàng hoá và dịch vụ về bảo vệ môi trường và quản lý tài nguyên, ứng phó với biến đổi khí hậu) theo quy luật cung - cầu của thị trường. Đặc biệt, cách tiếp cận thị trường khuyến khích các hành vi thông qua các tín hiệu thị trường hơn là các hướng dẫn, chỉ thị của Nhà nước. Chính sách của Hoa Kỳ thiên về việc khuyến khích các sáng kiến tuần hoàn và nhân rộng các điển hình tuần hoàn tốt. 
Thị trường rác thải điện tự tại Bang Colorado là một ví dụ điển hình của cách tiếp cận này để xây dựng KTTH. Cụ thể, năm 2013, việc chôn lấp rác thải điện tử bị cấm tại Bang Colorado. Ngay lập tức đã xuất hiện các doanh nghiệp đứng ra thu gom và tái chế rác thải điện tử. Như vậy, một thị trường với người mua là các hộ gia đình và người bán là các công ty cung cấp dịch vụ đã được hình thành. Kết quả là môi trường được bảo vệ, xã hội có thêm công ăn việc làm, Nhà nước không mất chi phí xử lý ô nhiễm do rác thải điện tử và rác thải được tuần hoàn xử lý. Việc các thị trường tương tự như vậy liên tục được hình thành đã khiến thu gom và xử lý rác thải trở thành một lĩnh vực sôi động và lợi nhuận cao đối với các nhà đầu tư tại Mỹ, từ đó xuất hiện các tỷ phú rác nổi tiếng như Wayne Huizenga của Công ty Quản lý chất thải (Waste Management) và Maria Rios của Công ty Chất thải quốc gia (Nation Waste) [26].

Cộng hòa Trung Quốc và Nhật Bản là hai quốc gia đầu tiên tại châu Á đưa ra các chính sách chính thức về KTTH ở cấp Nhân dân độ quốc gia [31]. Trung Quốc triển khai nền KTTH bằng cách đưa KTTH vào các kế hoạch của chính phủ Trung trong một số năm gần đây với ưu tiên chính nhằm vào cấp độ các thành phố. Theo đó, Trung Quốc triển khai Hoa KTTH trên toàn bộ nền kinh tế có hệ thống ở ba cấp độ đã được định hình: quy mô vĩ mô (thành phố, tỉnh và huyện), trung gian (khu vực cộng sinh) và quy mô vi mô (đối tượng cụ thể như doanh nghiệp) với một số lĩnh vực trọng tâm chính trong các hệ thống công nghiệp, môi trường xây dựng, cơ sở hạ tầng đô thị và hệ sinh thái.

Chiến lược KTTH của Trung Quốc được triển khai ở ba cấp độ: Thúc đẩy sản xuất sạch ở phạm vi doanh nghiệp, trong các khu công nghiệp triển khai hệ sinh thái công nghiệp, ở cấp khu vực phát triển các thành phố sinh thái. Chiến lược này đã được thử nghiệm trong bảy lĩnh vực công nghiệp và được thực hiện tại 13 khu công nghiệp, và kể từ năm 2005, tại 10 thành phố sinh thái và tỉnh sinh thái (Bắc Kinh, Thượng Hải, Trùng Khánh, Quý Dương, Ninh Ba, Hà Bắc, Đồng Lăng, Liêu Ninh, Sơn Đông và Giang Tô) dưới sự chỉ đạo của Ủy ban Cải cách và Phát triển Quốc gia.

Nhật Bản Chính phủ Nhật Bản đã xây dựng một khung pháp lý toàn diện nhằm đưa đất nước này hướng tới một xã hội dựa trên việc tái chế từ những năm 2000. Đạo luật về việc thành lập một xã hội dựa trên tái chế (The Basic Law for Establishing a Recycling-Based Society) có hiệu lực vào năm 2002 cung cấp các mục tiêu định lượng để tái chế và phi vật chất hóa trong dài hạn cho xã hội Nhật Bản.

Nhờ vậy, ngay sau đó tỷ lệ tái chế của Nhật Bản đã đạt được kết quả vượt trội: Nước này tái chế tới $98 \%$ kim loại [32] và trong năm 2007, chỉ có $5 \%$ chất thải của Nhật Bản phải sử dụng phương pháp chôn lấp, so với con số $48 \%$ đối với Vương quốc Anh vào năm 2008. Luật tái chế thiết bị của Nhật Bản đảm bảo rằng phần lớn các sản phẩm điện và điện tử được tái chế, so với con số $30 \%$ - 40\% ở Châu Âu [32]. Trong số các thiết bị này, $74 \%-89 \%$ vật liệu chứa trong đó được thu hồi [33]. Quan trọng hơn, phần lớn các vật liệu này được quay trở lại phục vụ cho mục đích sản xuất các sản phẩm cùng loại [34]. Tất cả những điều này tạo tiền đề cho Nhật Bản triển khai một nền kinh tế tuần hoàn.

Khi nói đến việc thực sự làm cho nền KTTH có thể hoạt động, tính toàn diện và hợp tác là trọng tâm của hệ thống tuần hoàn tại Nhật Bản. Cộng đồng cũng đóng một vai trò quan trọng bằng cách tách rời các vật liệu tái chế, trả phí tái chế trực tiếp và đối với các công ty có sự hạch toán khi cần thiết. Các nhà sản xuất thực hiện nghĩa vụ của họ bằng cách sử dụng nhiều vật liệu tái chế hơn và tạo ra các sản phẩm lâu dài hơn, dễ sửa chữa và tái chế hơn.

Hệ thống KTTH ở Nhật Bản có ba tính năng chính:

-Hệ thống thu hồi thân thiện với người tiêu dùng: hệ thống thu thập các thiết bị cũ để tái chế đảm bảo đầy đủ, dễ sử dụng. Các thiết bị cũ được thu thập do các nhà bán lẻ trong cửa hàng hoặc khi giao một thiết bị mới. Đối với thiết bị công nghệ cũ, nhà sản xuất có thể được yêu cầu thu thập lại, việc này do chính quyền địa phương đảm nhận .. Đây là một thói quen được hình thành trên khắp Nhật Bản, điều này khiến cho tư duy về KTTH được hiểu rõ và được sử dụng rộng rãi.

-Người tiêu dùng trả phí trước: đối với thiết bị điện tử, các chi phí vận chuyển và phục hồi được thanh toán tại điềm mua, ngoài ra hình phạt cho việc vứt rác bừa bãi cũng được tăng cao.

-Cơ sở hạ tầng tái chế là đồng sở hữu: luật pháp yêu cầu liên minh các nhà sản xuất điều hành các nhà máy tháo gỡ, đảm bảo họ được hưởng lợi trực tiếp từ việc thu hồi vật liệu và các bộ phận. Do đó, các công ty đầu tư lâu dài vào cơ sở hạ tầng tái chế. Và bởi vì họ sở hữu cả các cơ sở sản xuất và phục hồi, các công ty gửi các nhà thiết kế sản phẩm đến các nhà máy tháo gỡ để tiết kiệm thời gian khi phải tách rời một sản phẩm được thiết kế kém. Một số công ty thậm chí còn đưa các nguyên mẫu qua quy trình tháo gỡ để đảm bảo chúng có thể dễ phục hồi.

Hệ thống triển khai KTTH của Nhật Bản được xây dựng dựa trên giả định hợp tác, nhưng hệ thống này cũng khuyến khích mọi người phải thực hiện đúng. Kết quả là việc áp dụng các triết lý của KTTH không chỉ giúp các hoạt động kinh tế vận hành tốt mà còn mang lại lợi nhuận khổng lồ: nền kinh tế tái sử dụng và tái chế của Nhật Bản trị giá 163 tỷ bảng năm 2007 (7,6\% GDP) và tạo ra việc làm cho hơn 650.000 người [32].

Hàn Quốc Hàn Quốc đã ban hành luật về tuần hoàn tài nguyên từ các sản phẩm điện tử và phương tiện giao thông từ năm 2007, sau đóban hành luật về thúc đẩy tiết kiệm và tuần hoàn tài nguyên năm 2008 và hàng loạt các luật khác liên quan $[35,36]$. Theo đó, việc tuần hoàn tài nguyên bao gồm "nhận diện tài nguyên tuần hoàn", "quản lý hiệu suất tuần hoàn tài nguyên", "đánh giá tính khả dụng của chu kỳ tuần hoàn" và "phí xử lý chất thải". Ngoài ra, Bộ luật này cũng bao gồm các chính sách để giảm lượng chất thải trong tất cả các quy trình từ sản xuất, phân phối, tiêu thụ cho đến xử lý sản phẩm và để thúc đẩy tái chế.

"Quản lý hiệu suất tuần hoàn tài nguyên" sẽ được áp dụng cho các nhà máy xả thải được chỉ định trên 100 tấn 
nghệ tái chế tại các làng nghề còn cũ và lạc hậu, cơ sở hạ tầng yếu kém, quy mô sản xuất nhỏ, trình độ nhận thực của người dân và cơ sở sản xuất về tác hại của ô nhiễm môi trường còn hạn chế.

Gần đây tiếp tục xuất hiện một số mô hình, mới hướng đến gần hơn với Kinh tế tuần hoàn, đó là các mô hình khu công nghiệp sinh thái tại Ninh Bình, Cần Thơ và Đà Nẵng, giúp tiết kiệm 6,5 triệu USD/năm [38]; sáng kiến Không xả thải ra thiên nhiên (Zero Waste to Nature) do VCCI khởi xướng; sáng kiến tái chế nắp bia Tiger thành sắt làm cầu tại Tiền Giang (giúp thu hồi sắt); ống hút làm từ cỏ và gạo thay thế cho ống hút nhựa (giúp giảm phát thải nhựa), mô hình tái chế rác thải nhựa làm vật liệu xây dựng của công ty Upp!; mô hình chế biến phụ phẩm thủy sản (vỏ tôm, đầu tôm,...) tạo ra Chitosan và $\mathrm{SSE}$, đặc biệt là sự xuất hiện của Liên minh Tái chế Bao bì Việt Nam (Pro Việt Nam) gồm 9 công ty: Coca-Cola Việt Nam, Friesland Campina, La Vie, Nestlé Việt Nam, NutiFood, Suntory PepsiCo Việt Nam, Tetra Pak Việt Nam, TH Group và $\mathrm{URC}$ Việt Nam,.... Các điển hình này cần được tổng kết, đánh giá dựa trên những nguyên tắc, tiêu chí cơ bản của kinh tế tuần hoàn, từ đó bổ sung hoàn thiện và nhân rộng.

4.2. Một số giải pháp phát triển kinh tế - xã hội Việt Nam theo mô hình KTTH trong thời kỳ công nghệ 4.0

Trong thập niên 2020-2030 và xa hơn nữa, Việt Nam cần tập trung thúc đẩy sự chuyển dịch từ Kinh tế tuyến tính sang Kinh tế tuần hoàn, hoà chung với xu hướng của cộng đồng thế giới. Trên cơ sở tổng hợp kinh nghiệm quốc tế và thực tiễn tại Việt Nam, để phát triển nền kinh tế tuần hoàn cần có các giải pháp đồng bộ.

i) Trước hết, nhà nước cần làm tốt vai trò kiến tạo để doanh nghiệp và người dân đóng vai trò trung tâm trong phát triển nền kinh tế tuần hoàn thông quan hoàn thiện thể chế, chính sách, pháp luật khuyến khích thúc đẩy phát triển các ngành công nghiệp tái chế.

Đồng thời, cần thực thiện tốt công tác quy hoạch, thực hiện lồng ghép với KTTH vào kế hoạch phát triển kinh tế-xã hội 5 năm 2021-2015 và Chiến lược phát triển kinh tế - xã hội 10 năm 2021-2030. Bên cạnh đó, vai trò kiến tạo của nhà nước cũng thể hiện qua việc dẫn dắt, thông qua việc đẩy mạnh chi tiêu công xanh (Green Public Procurement - GPP).

ii) Xây dựng lộ trình KTTH. Kinh nghiệm của các nước Anh, Pháp, Phần Lan, Hà Lan và gần đây là Malaysia cho thấy cần có lộ trình để thực hiện $\mathrm{KTTH}$. Các lộ trình này thường dài từ 15-20 năm, nêu rõ các mục tiêu và các quy định cụ thể cho từng giai đoạn nhỏ. Theo đó, Việt Nam có thể cân nhắc đưa cả hai cách tiếp cận thực hiện KTTH của quốc tế vào lộ trình của mình. Đó là:

(a) Cách tiếp cận theo nhóm ngành, sản phẩm, nguyên liệu hoặc vật liệu (Group of sectors, products, materials and substances) - có thể gọi tắt là tiếp cận theo loại vật liệu: Tập trung tuần hoàn một số vật liệu nhất định, khuyến khích các sáng kiến và điển hình tốt, phù hợp với đặc điểm của lĩnh vực đó, từ đó nhân rộng. Ví dụ, xây dựng lộ trình "không rác thải nhựa dùng một lần" và "không rác thải" (tại Malaysia, Canada), cách tiếp cận dựa vào thị trường (tại Mỹ, Úc),...

(b) Cách tiếp cận theo quy mô kinh tế (Systemic economy-wide implementation): Thành lập các không gian địa lý như khu công nghiệp, các thành phố kiểu mẫu, những hoạt động kinh doanh và sản xuất trong các không gian này được thiết kế sao cho kết nối với nhau thành các vòng tuần hoàn, sau đó nhân rộng các mô hình thành công (kinh nghiệm Đan Mạch, Hàn Quốc, Trung Quốc, Nhật Bản, Canada,...);

Bên cạnh đó, lộ trình cũng cần tiếp tục thực hiện các nội dung khác của KTTH, như khuyến khích năng lượng tái tạo, thúc đẩy sử dụng các sản phẩm thân thiện với môi trường, hoàn thiện và phát triển các mô hình $\mathrm{KTTH}$ đã có tại Việt Nam.

Đặc biệt, các lộ trình KTTH trên thế giới đều xác định rõ doanh nghiệp chính là động lực trung tâm thực hiện KTTH. Với Việt Nam, VCCI là đại diện cho cộng đồng doanh nghiệp và cũng 
được coi là tổ chức tiên phong trong lĩnh vực KTTH. Vì thế, Bộ Tài nguyên và Môi trường sẽ thực hiện xây dựng Đề án thúc đẩy thực hiện kinh tế tuần hoàn ở Việt Nam, mong muốn phối hợp chặt chẽ với VCCI, các doanh nghiệp và các tổ chức quốc tế trong việc xây dựng và thực hiện lộ trình KTTH.

iii) Mở rộng trách nghiệm của nhà sản xuất và thúc đẩy các thị trường tái chế. Song song với việc hạn chế các rác thải khó tái chế như rác thải nhựa, cách tiếp cận thứ hai (tiếp cận theo loại vật liệu) của KTTH còn bao gồm việc thúc đẩy hình thành và phát triển các thị trường tái chế, như thị trường tái chế giấy, tuần hoàn kim loại... Theo đó, việc sử dụng cách tiếp cận dựa vào thị trường (Market-based Approach - MBA) để tạo điều kiện cho việc hình thành và phát triển các thị trường này, như kinh nghiệm của Hoa Kỳ, nên được tính đến. Với Việt Nam, một số giải pháp chính sách trong nhóm này có thể bao gồm: tiếp tục phát triển Mở rộng trách nhiệm của nhà sản xuất (Extended Producer Responsibility - EPR) và hình thành, phát triển các Thị trường nguyên vật liệu thứ cấp.

iv) Xây dựng hệ thống cơ sở dữ liệu về KTTH. Các dữ liệu về KTTH không chỉ là tập hợp thông tin về các điển hình hoặc sáng kiến tuần hoàn tốt để xem xét và nhân rộng, mà còn bao gồm cả các dữ liệu quan trọng, giúp theo dõi mức độ tuần hoàn của nền kinh tế (như tỉ lệ tái chế chất thải rắn, tỉ lệ tái sử dụng chất thải, hiệu suất tuần hoàn tài nguyên,...). Đây là các dữ liệu quan trọng để phục vụ cho việc quản lý và điều chỉnh việc thực hiện KTTH.

Thực tế là tất cả các nước hàng đầu về KTTH trên thế giới đều có hệ thống cơ sở dữ liệu rất tốt về KTTH, trong khi đó ngay cả những dữ liệu cơ bản như tỉ lệ tái chế chất thải rắn qua các năm thì Việt Nam vẫn chưa thống kê được.

v) Phát triển công nghệ, kinh tế số và cách mạng công nghiệp 4.0 gắn liền với KTTH. Trên thực tế, nhiều sáng kiến tuần hoàn mới có thể xuất hiện từ sự phát triển của công nghệ. Ví dụ, tại Đài Loan, phần mềm cài trên điện thoại cho phép người dùng tích điểm khi thực hiện thu gom các chất thải tái chế. Sau đó, họ có thể sử dụng các điểm này để mua hàng tại nhiều siêu thị và cửa hàng thay cho tiền mặt. Điều này không những khuyến khích người dân tham gia thu gom và tái chế, mà còn giúp nâng cao nhận thức của người dân.

Tuy nhiên, cần lưu ý tác động của phát triển công nghệ tới KTTH. Ví dụ, việc điện thoại thông minh ngày càng trở nên phổ cập và vòng đời của điện thoại ngắn đi do việc thường xuyên nâng cấp về công nghệ, cung với đó lượng rác thải như pin li-ion, một loại rác thải nguy hại hiện chưa tái chế được ở Việt Nam sẽ tăng nhanh.

Sự phối hợp giữa Bộ Tài nguyên và Môi trường với các Bộ ngành, sự hỗ trợ của các cộng đồng doanh nghiệp và các tổ chức quốc tế để nghiên cứu sâu hơn về Kinh tế tuần hoàn, xác định chi tiết nội dung và cách thức thực hiện các giải pháp kể trên là hết sức cần thiêt.

\section{Kết luận}

Chuyển dịch từ Kinh tế tuyến tính sang Kinh tế tuần hoàn đang là xu thế chung của cộng đồng thế giới và Việt Nam cũng không nằm ngoài $x u$ thế đó. Đó là cách tốt nhất để phá vỡ mối liên hệ lâu nay giữa tăng trưởng kinh tế và các ảnh hưởng tiêu cực tới cạn kiết tài nguyên, ô nhiễm và suy thoái môi trường, một cách khác, không còn phải đánh đổi giữa phát triển kinh tế và bảo vệ môi trường, thực hiện được đồng thời nhiều mục tiêu của phát triển bền vững. Trong bối cảnh đẩy mạnh công nghiệp hóa, hiện đại hóa, đô thị hóa nền kinh tế, gia tăng dân số và thay đổi trong phương thức tiêu dùng đã, đang và sẽ dẫn đến những hệ quả về cạn kiệt, suy thoái và ô nhiễm ngày càng tăng thì lựa chọn cách tiếp cận chuyển đổi sang nền kinh tế tuần hoàn cần được xem là một tất yếu phải thực hiện nhằm đạt được mục tiêu "phát triển kinh tế nhanh, bền vững", rút ngắn khoảng cách phát triển so với các quốc gia trong khu vực và trên thế giới. Để thực hiện được định hướng này đỏi hỏi phải có sự nỗ lực của mọi thành phần trong xã hội, đặc biệt doanh nghiệp là động lực trung tâm, nhà nước đóng vai trò kiến tạo, dẫn dắt và cộng đồng tham gia thực hiện để thay đổi cả về nhận thức và hành vi của toàn xã hội. 


\section{BÀI BÁO KHOA HỌC}

\section{Tài liệu tham khảo}

1. Global Footprint Network (2018), National Footprint Accounts. https://data.footprintnetwork.org

2. Ellen MacArthur Foundation (2016), The New Plastics Economy, Rethinking the Future of Plastics. Ellen MacArthur Foundation, World Economic Forum \& McKinsey Center for Business and Environment. https://www.ellenmacarthurfoundation.org/assets/downloads/EllenMacArthurFoundation_TheNewPlasticsEconomy_Pages.pdf

3. CREM (2018), Scoping study circular economy Vietnam, Amsterdam, the Netherlands.

4. Binh, T., Oanh, K., (2019), Paradox of coal industry: massive export, massive import. https://customsnews.vn/paradox-of-coal-industry-massive-export-massive-import-10003.html (accessed 01 March, 2019).

5. IEA (2019), International energy statistics. https:/www.eia.gov/beta/international/data/browser/

6. Bộ Tài Nguyên và Môi trường (2011), Báo cáo môi trường quốc gia 2011: Chất thải rắn.

7. Bộ Tài Nguyên và Môi trường (2015), Báo cáo hiện trạng môi trường quốc gia giai đoạn 20112015.

8. Bộ Tài nguyên và Môi trường (2017), Báo cáo hiện trạng môi trường quốc gia 2017: Chuyên đề Quản lý chất thải.

9. Kaza, S.,Yao, L., Bhada-Tata, P., Woerden, F.V., (2018), What a waste 2.0: a global snapshot of solid waste management to 2050. World Bank Publications.

10. Jambeck, J.R., Geyer, R., Wilcox, C., Siegler, T.R., Perryman, M., Andrady, A., Narayan, R., Law, K.L., (2015), Plastic waste inputs from land into the ocean. Science, 347 (6223),768-771.

11. World Bank (2016), The cost of air pollution: Strengthening the economic case for action. Washington.

12. World Bank (2019), Vietnam: Toward a Safe, Clean, and Resilient Water System. Washington, DC.

13. IPCC (2007), Climate Change 2007: Impacts, Adaptation and Vulnerability. Contribution of Working Group II to the Fourth Assessment Report of the International Panel on Climate Change. M.L. Parry, O.F. Canziani, J.P. Palutikof, P.J. van der Linden and C.E. Hanson (eds.). Cambridge, UK: Cambridge University Press.

14. World Bank (2011), Vietnam - First Climate Change Development Policy Operation Program. Washington D.C: The World Bank.

15. DARA international (2012), Climate vulnerability monitor 2nd Ed. Country study: Vietnam. http://daraint.org/climate-vulnerability-monitor/climate-vulnerability-monitor-2012/country-studyvietnam/

16. Government of the Netherlands, From a linear to a circular economy. https://www.government.nl/topics/circular-economy/from-a-linear-to-a-circulareconomy?fbclid=IwAR1QAaaoW8mUXc5wbNvJV7b9Ysf3UNhDUspp0YmP0eUFaDj_xXC7ua Cllgc

17. Stahel, W.R., Reday-Mulvey, G., (1976), The potential for substituting manpower for energy; report to DG V for Social Affairs. Commission of the EC, Brussels (research contract No. 760137 programme of research and Actions on the development of the Labour Market).

18. Ellen MacArthur Foundation (2015), Delivering the circular economy: a toolkit for policymakers.https://www.ellenmacarthurfoundation.org/assets/downloads/publications/EllenMacArthurFoundation_PolicymakerToolkit.pdf

19. Ellen MacArthur Foundation (2017), Inforgraphic: Circular economy system diagram. 
20. Nam, N.H., Hue, H.T., Phuong, N.T.B., (2019), Kinh tế tuần hoàn và sự chuyển dịch tất yếu. Tạp chí Khoa học ĐHQGHN: Nghiên cứu Chính sách và Quản lý, 35 (3), 21-28.

21. EC (2016), Circular economy: Closing the loop - An EU action plan for the circular economy. European Commission.

22. European Commission (2019), Report from the Commission to the European Parliament, the Council, the European Economic and Social Committee and the Committee of the Regions on the implementation of the Circular Economy Action Plan. Brussels.

23. Cramer, J., (2014), Moving towards a circular economy in the Netherlands: challenges and directions. https://wp.hum.uu.nl/wp-content/uploads/sites/32/2015/04/Paper-HongKong-JC-april2014.pdf.

24. Schnurer, H., (2002), German Waste Legislation and Sustainable Development: Development of waste legislation in Germany towards a sustainable closed substance cycle, International Institute for $\quad$ Advanced $\quad$ Studies $\quad$ (IIAS) in Kyoto/Japan.https://www.bmu.de/fileadmin/bmu-import/files/pdfs/allgemein/application/pdf/entwicklung_abfallrecht_uk.pdf. andhttps://www.bmu.de/fileadmin/bmu-import/files/pdfs/allgemein/application/pdf/entwicklung_abfallrecht_uk.pdf

25. BMU (2011), Closed-loop waste management: Recovering wastes - conserving resources. Berlin, Germany.https://gnse.files.wordpress.com/2012/10/waste-management.pdf

26. Nam, N.H., Huê, H.T., Nhạn, N.T.T., (2018), Cách tiếp cận thị trường trong quản lý tài nguyên, bảo vệ môi trường và ứng phó với biến đổi khí hậu: Kinh nghiệm Hoa Kỳ. Tạp chí Khoa học ĐHQGHN: Nghiên cứu Chính sách và Quản lý, 34 (4), 43-50.

27. OECD (2002), OECD Environmental Performance Reviews: Japan 2002. OECD Environmental Performance Reviews, Paris.

28. McDowall, W., Geng, Y., Huang, B., Barteková, E., Bleischwitz, R., Türkeli, S., Kemp, R., Doménech, T., (2017), Circular economy policies in China and Europe. Journal of Industrial Ecology, 21 (3), 651-661.

29. Lah, O., (2016), Circular Economy Policies and Strategies of Germany (Towards a Circular Economy: Corporate Management and Policy Pathways). ERIA Research Project Report 2014-44, Jakarta: ERIA, 59-74.

30. CCME (2018), Strategy on zero plastic waste. https://www.ccme.ca/files/Resources/waste/plastics/STRATEGY\%20ON\%20ZERO\%20PLASTIC\%20WASTE.pdf

31. Reike, D., Vermeulen, W.J., Witjes, S., (2018), The circular economy: New or refurbished as CE 3.0? Exploring controversies in the conceptualization of the circular economy through a focus on history and resource value retention options. Resources. Conservation and Recycling,135,246-264.

32. Ministry of the Environment, Government of Japan (2010), Establishing a sound materialcycle society: Milestone toward a sound material-cycle society through changes in business and life styles.

33. WEEE Forum (2012), The challenge of transposing WEEE II into national law. http://www.weee-forum.org/news/the-challenge-of-transposing-weee-ii-into-national-law

34. Panasonic. Our Approach to Resources Recycling. https://www.panasonic.com/global/corporate/sustainability/eco/resource_sp.html

35. Korean Government (2007), Act on the Resource Circulation of Electrical and Electronic Products and Vehicles.

36. Korea Ministry of Environment. Extended Producer Responsibility (EPR). 


\title{
BÀI BÁO KHOA HỌC
}

http://eng.me.go.kr/eng/web/index.do?menuId=372

37. Korean Ministry of Environment (2017), Enforcement of the resource recycling law. http://www.moleg.go.kr/english/korLawEng?pstSeq=47557

38. UNIDO (2019), Eco-Industrial Park Initiative for Sustainable Industrial Zones in Vietnam.https://eipvn.org/e-library/publications/.

\section{ORIENTATION FOR A PERFECT ECONOMIC PLATFORM IN THE 4.0 INDUSTRIAL REVOLUTION}

\author{
Tran Hong $\mathbf{H a}^{1}$ \\ ${ }^{1}$ Minister of the Ministry of Natural Resources and Environment
}

\begin{abstract}
Vietnam, after a long period of development based on cheap labor resources and resources, has achieved a great deal of socio-economic development. However, Vietnam is facing many serious challenges on resource depletion, environmental pollution and climate change. Therefore, Vietnam needs to show its responsibility in addressing global challenges due to environmental pollution, climate change and improving the competitiveness of the economy. Establishing a society that is consciously reused materials instead of raw materials, minimizing the exploitation of natural resources, maximizing the value of resources, minimizing waste and exhausted gas into the environment, protecting people's health. It is necessary to orient an economy following the advanced trend to reduce risks of overproduction crisis, scarcity of resources, creating new employment and investment opportunities, reducting of production costs and increasing supply chains. Based on the practical situation of Vietnam and experiences from developed countries, the circulation economy is an effective solution for the country's socio-economic sustainable development, it is suitable to small and crowded coutry which is limited and exhausting resources, and decline environment. Vietnam needs to focus on promoting the transition from linear economy to circulation economy. This article provides the basis orientation to promote the development of circulation economy for Vietnam as an indispensable part of the development process.
\end{abstract}

Keywords: Circulation economic, Resource depletion, Environmental pollution, Climate change, Sustainable development. 